INTERNATIONAL JOURNAL OF MULTidisciplinARY RESEARCH AND ANALYSis

ISSN(print): 2643-9840, ISSN(online): 2643-9875

Volume 05 Issue 02 February 2022

DOI: 10.47191/ijmra/v5-i2-26, Impact Factor: 6.072

Page No. 414-419

\title{
Knowledge and Practices of Medical Officers on Medical Near Misses in a Tertiary Care Hospital, Sri Lanka
}

\author{
A.D.H Jayathilake ${ }^{1}$, P. Karthikeyan ${ }^{2}$, S.M Arnold ${ }^{3}$ \\ 1,2,3 Ministry of Health, Sri Lanka
}

\begin{abstract}
Background: Near misses are the most crucial and valuable elements in the prevention of potentially unintentional harm in patients service provision. Reporting incidents is an essential component in inculcating patient safety culture. In developed countries medical services are now focused on vigilance on such near misses. This paradigm shift of medical service provision paved the way for patient safety domain in medical service design. Patient safety has now become one of the six constituents of service quality. Continuous vigilance for possible near misses will disclose them beforehand. This will avoid triggering the chain reaction that bring about disastrous patient outcomes. Favorability of existing practices and knowledge on near misses are two key determinants of the successful safety culture initiatives.

Methods: Cross sectional descriptive study carried out at the Colombo South Teaching Hospital. A stratified sample of medical officers was selected out of those involved in the patient care services. Stratification was done according to the service categories such as specialist grade, grade medical officers and intern officers. Most reason salary sheet used as the sampling frame to select medical officers randomly from each stream. A pretested self-administered questionnaire was used, as the study instrument. The questionnaire contained two main sections as knowledge and practices. Data analysis done using PSSP software.
\end{abstract}

Results: Over all response rate was $90 \%$. Over $94 \%$ of respondents had satisfactory or good level of knowledge. $88 \%$ did not report near misses. Overall, a considerable percentage $(n=168,53 \%)$ had poor level of practices. Only $5.9 \%(n=19)$ had good level of practices. In the specialist grade medical officers $41.1 \%$ had poor practices despite none of the specialists having a poor knowledge. Highest level of poor practices ( $n=128,70.8 \%$ ) was seen in grade II medical officers.

Conclusions: The study reveals that majority of medical officers at CSTH have a satisfactory knowledge on the near misses as predecessors of the of patient harm. continuous engagement in near misses' surveillance in an organization is an integral component in a patient safety culture.

However, the practices are not satisfactory in a majority.

KEY WORDS: Near misses, surveillance, incident reporting, safety culture, medical officers, hospital

\section{INTRODUCTION}

Near misses or close calls are forerunners of iatrogenic patient injuries. Near misses compromise safety during various therapeutic procedures. These injuries are unintended outcomes of treatment. Most of these unintended medical errors do not result in patient injury. ${ }^{1}$ However injuries are "tip of the iceberg". There are accidents "dormant" within the system for many years before they combine with active failure and local triggers to create an accident opportunity. ${ }^{2}$ This, yet to happen group, usually goes unnoticed unless they cause overt injury. This category encompasses, so called near misses.

Near misses are the predecessors of patient harm. It is also called a close call. An incident which did not reach the patient. ${ }^{3,4} \mathrm{~A}$ patient safety incidents (PSI) is defined as any unintended or unexpected incident which could have or did lead to harm for one or more patients receiving care. ${ }^{5}$ According to British Institute of Radiology a near miss is "a potential radiation incident that was detected and prevented before treatment delivery. However, mistakes in plans, calculations etc, do not constitute near misses if they were detected and corrected as part of the checking procedure before authorizing for clinical use". It also says that, the term 'miss' is used in the context of falling short of being an actual radiation incident, rather than in the narrower sense of a 


\section{Knowledge and Practices of Medical Officers on Medical Near Misses in a Tertiary Care Hospital, Sri Lanka}

geometric miss. ${ }^{6}$ World Health Organization defines "near miss" or "close cells" as serious error or a mishap that has the potential to cause an adverse event. ${ }^{7}$

Patient safety initiatives that are presently in operation at global scale have made the medical profession aware on the safer medical practices all over the world. Medical errors, their incidence and gravity of the issue came into attention with reports of institute of medicine in 1999 with the publication of "To Error is human; building a safer health system". ${ }^{8}$ In the ice breaking finding, the authors described an estimated 44,000 to 98,000 deaths in America annually. Following this, many articles and studies described similar study finding. The three reports that change the global health care vision from primary health packages to quality and safety dimensions are as follows ${ }^{9}$; The institute of medicine's (IOM) National Round Table on Health Care Quality Report, "The Urgent Need to Improve Health Care Quality",

In United States, Wenzel has estimated that CLABSI (Central Line Associated Bloodstream Infections) affect an estimated 48,000 ICU patients every year and of them $50 \%$ die. ${ }^{10}$ In the United Kingdom, over 1000people died from adverse drug events in 2001. It has been suggested that $75 \%$ of these errors are preventable. ${ }^{11}$ It is estimated that economic losses up to 2.5 billion of Euros occurred due to compensations for medical mistakes in Italy. Development of a common international framework for classification, adverse events reporting near misses is one of technical components WHO's global strategy.

In the early administrative guideline of the ministry of health, prime focus was on basic health care curative package. This is seen in health manual of 1994. In the latter part of 1990's Japanese "five S" concepts appeared in non-health business sectors of Sri Lankan market. In the government health services, Castle Street Hospital for woman winning a quality award became an eye opening event.

With the establishment of Quality Secretariat under the Ministry of Health, there is an ongoing discussion on this topic. A circular letter No 01-29/2009 has been issued by the Ministry of Health as an initial step. By this circular for the first-time instructions were issued to collect data on patient safety issues. The circular letter also advices to collect data on near-misses, adverse events and patient accidents. However, in Sri Lanka exact figures on near-misses are not known.

Some near misses' cases in which no harm at all, illustrates important system problems and have tremendous learning value for the organization. ${ }^{12}$ There are two types of victims of medical near misses and errors. The largest impact is on patients and their loved ones; the toll is best measured in anxiety, harm, and death. Service providers are "second victims" of unsafe systems that let them down when they most needed the support. Exact evaluation on the survivors of medical near misses is not done in Sri Lanka. In one study done in Australia shows that most of patients experiencing adverse events are elderly people. ${ }^{13}$ It is also pointed out that death toll, permanent and temporary disability are highest in aging population.

The medical error affects the care giver too. There court cases that affected the care givers. Unnecessary fears of reprimand can make Health Care Workers (HCWs) adhering to rigid protocols and legislations. Hospitals with an error management culture aims to learn from errors rather than repeat them. In this culture, employees are encouraged to report and discuss errors and near misses. Rather than avoiding the problem, this allows people to confront it. Near misses will lead to sensitizing the HCWs and thereby leading to prevention or to mitigate effects of medical errors and mistakes.

Most of the risk of factors are innocent human errors. ${ }^{14}$ Lack of leadership commitment is one major risk factor. ${ }^{15}$ In developing a sustainable error prevented hospitals systems committed leader is a strong positive factor. Medical profession all over the world is maintaining high hierarchical gaps. ${ }^{16}$ They are less reluctant to discuss mistakes and this is an identified risk factor for closely communicating organizational safety culture. Culture of blames and communication gaps are important risk factors that harbor influence negative patient outcomes. ${ }^{17}$ Communication gaps accounted for around $15 \%$ of the potential adverse events. Communication within care teams, between the teams and, or their relation have given rise to potential and real-life medical errors.

\section{METHODS}

This research adopted the descriptive, cross-sectional method to assess knowledge and practices on near misses among medical officers. The study was carried out in Colombo South Teaching Hospital, Kalubowila (CSTH). The CSTH is a tertiary care hospital where all categories of medical officers from specialist grade to intern medical officers provide patient care services. The hospital is under line ministry administration. It has a university professorial unit also. academically high profile. very senior experienced medical officers in all grade categories. 


\section{Knowledge and Practices of Medical Officers on Medical Near Misses in a Tertiary Care Hospital, Sri Lanka}

The study population consisted of medical officers attached to the Colombo South Teaching Hospital. Medical Officers who are presently attached to the medical officers directly involved in the treatment of patients care activities were included. The calculated sample size was 352 medical officers. As there were 565 medical officers who fulfilled the eligibility criteria. The study sample was selected propitiate to the total number in each category of medical officers.

Table 1: Distribution of medical officers by category

\begin{tabular}{lll}
\hline Category of medical officers & $\begin{array}{l}\text { Number of officers of } \\
\text { available }\end{array}$ & $\begin{array}{l}\text { Number of officers of } \\
\text { selected }\end{array}$ \\
\hline Specialist Grade & 75 & 47 \\
Grade-I & 100 & 63 \\
Grade-II & 322 & 200 \\
Preliminary grade & 19 & 11 \\
Intern Medical Officers & 49 & 31 \\
\hline Total & 565 & 352 \\
\hline
\end{tabular}

The name list of medical officers belonging to each category was prepared based on the most current pay sheet. The medical officers selected randomly for each category using the name list for each category as the sampling frame this ensured that a representative sample was obtained covering all eligible units. the selected medical officers were contacted and questionnaires was administrated during working hours. If the selected medical officers were randomly selected using the same sampling frame. This was done until the required number of medical officers were recruited.

A self-administered questionnaire used as the study instrument. Self-administered this selected since medical officers being intellectuals and data collection can be completed with in the specified short period of time. The questionnaires contained three parts; Part -1 Sociodemographic data of the study population, Part-2 knowledge on the near misses, Part-3 Practices on the near misses. Pre testing carried out in a teaching hospital with a similar background. Data was collected on week days since certain medical officers are off duty on weekends and public holidays.

Data was analyzed using Statistical Package for Social Sciences. A scoring system was designed to allocate a score for each response of the close ended knowledge questions. There were 10 questions to assess the knowledge component of the participants. Correct answers given 2 marks and incorrect 0 . Total score rages from $0-20$ and the percentage was calculated for each participant. Based on the percentage scoring, it was further categorizing into four levels as shown below.

There were 10 questions regarding self assed work practice. Correct response given 2 marks and incorrect response given o marks. Total score ranged from 0-20. Percentage calculated for each participant.

\section{RESULTS}

The sample size for the study was 362. Even though all eligible medical officers consented for participation 317 returned the completed questionnaire giving an overall response rate of $90 \%$.

Following categorization was used to categorize the knowledge scores.

$\begin{array}{lll}00-49 \% & - & \text { Poor knowledge } \\ 50-74 \% & - & \text { Satisfactory knowledge } \\ 75-100 \% & - & \text { Good knowledge }\end{array}$

The average marks respondents got are summarized in table 2 . The mean knowledge score was 74 out of 100 and was expressed as $74 \%$. Range for the sample was from $30-100$ marks.

Table 2: Distribution by knowledge category

\begin{tabular}{lll}
\hline Category & Frequency & Percentage (\%) \\
\hline Good & 168 & 52.9 \\
Satisfactory & 130 & 41.2 \\
Poor Knowledge & 19 & 5.9 \\
Total & $\mathbf{3 1 7}$ & $\mathbf{1 0 0 . 0}$ \\
\hline
\end{tabular}




\section{Knowledge and Practices of Medical Officers on Medical Near Misses in a Tertiary Care Hospital, Sri Lanka}

A majority (88\%) did not routinely report near misses. $72 \%$ indicated that protocols are adhered the respective units. Of the respondents $54 \%$ indicated that in an undesired effect affecting a patient the responsibility is fixed to the staff involved. Only $28 \%$ routinely asked the nursing officers regarding re admissions to the unit. $43.8 \%$ indicated that they work under the pressure of somehow finishing the work load at your clinical practice (Table 3).

Table 3: Frequency distribution by practices in relation to near misses

\begin{tabular}{|l|l|l|l|}
\hline \multicolumn{2}{|l|}{ Practice } & \multicolumn{1}{|l|}{ Response } \\
\cline { 2 - 4 } & \multicolumn{1}{|l|}{ Yes (\%) } & No (\%) \\
\hline 1. & $\begin{array}{l}\text { Routine reporting the near misses or unintended patient injuries in a } \\
\text { register(correct practice) }\end{array}$ & 12.0 & 88.0 \\
\hline 2. & $\begin{array}{l}\text { Own or a national (standard) protocols that are adhered in the } \\
\text { unit(correct practice) }\end{array}$ & 72.0 & 28.0 \\
\hline 3. & $\begin{array}{l}\text { Adhere to short cut of recommended protocols in your clinical } \\
\text { practice at cSTH(Incorrect practice) }\end{array}$ & 56.2 & 43.8 \\
\hline 4. & $\begin{array}{l}\text { In an undesired effect affecting a patient, fix the responsibility on staff } \\
\text { involved(Incorrect practice) }\end{array}$ & 54.0 & 46.0 \\
\hline 5. & $\begin{array}{l}\text { Encountered diagnostic errors or medical errors during last 3 month } \\
\text { of practice(correct practice) }\end{array}$ & 36.0 & 64.0 \\
\hline 6. & $\begin{array}{l}\text { Adhere to hand washing practices before patient's } \\
\text { examination(correct practice) }\end{array}$ & 40.1 & 59.9 \\
\hline 7. & $\begin{array}{l}\text { Have adequate facilities for hand washing as expected in } \\
\text { ward/clinic(correct practice) }\end{array}$ & 52.1 & 47.9 \\
\hline 8. & Have an open culture in the unit(correct practice) & 41.9 & 58.1 \\
\hline 9. & $\begin{array}{l}\text { Work under the pressure of somehow finishing the work load at your } \\
\text { clinical practice(Incorrect practice) }\end{array}$ & 43.8 & 56.2 \\
\hline 10. & $\begin{array}{l}\text { Routinely ask the nursing officers regarding re admissions to the } \\
\text { unit(correct practice) }\end{array}$ & 28.1 & 71.9 \\
\hline
\end{tabular}

Correct response on practices (Yes or No) was given 2 marks and the incorrect response (Yes or No) was given 0 marks. Total score ranged from 0-20, and the percentage was calculated for each participant. Based on percentage scoring, it was further categorized into three levels as shown below.

Following scoring scale was used to categorize practices among the respondents.

$0-49 \%$ - Poor practice

50- $74 \%$ - Satisfactory practice

$75-100 \%$ - Good practice

Table 4: Distribution by level of practice

\begin{tabular}{|c|c|c|c|}
\hline Level of practice & Frequency & & Percentage \\
\hline Poor & & 168 & 53.0 \\
\hline Satisfactory & 130 & & 41.0 \\
\hline Good & & 19 & 6.0 \\
\hline Total & & 317 & 100.0 \\
\hline
\end{tabular}

Mean $=48.4$, Range $=0-80$

A considerable percentage $(n=168,53 \%)$ had poor level of practices. Only $5.9 \%(n=19)$ had good level of practices. (Table 4$)$

\section{DISCUSSION}

Medical officers are the key decision makers on patient care in the hospital. Other staff categories make decisions within the framework of area prescribed by medical officers such as nursing management framework of a patient. Frequency of legal actions, media reports and conflicts with patients on patient management are increasing. The root cause of these are perceived 


\section{Knowledge and Practices of Medical Officers on Medical Near Misses in a Tertiary Care Hospital, Sri Lanka}

errors and failures in patients' management. They are heard both in private and public sectors. In the present context globally the concept of "near misses" are now considered as an important component of quality of care. Therefore, in the Sri Lankan healthcare system should also take serious note on "near misses" in the path to improving quality of patient care.

The study was conducted as a descriptive cross-sectional study. The Colombo South Teaching Hospital was selected as the study setting since all categories of medical officers from specialists to intern medical officers work in a teaching hospital and representative sample could be taken. The name list of medical officers belonging to each category was prepared based on the most current pay sheet. The medical officers were selected randomly for each category using the name lists for each category as the sampling frame. This ensured that a representative sample was obtained covering all eligible units. Considering the feasibility and level of education of the respondents self-administered questionnaire was used as the study instrument. The questionnaire was prepared after extensive literature search and guidance from experts. The study instrument was pre tested before administering it to the study population.

The Colombo South Teaching Hosital is a line ministry teaching hospital with academically rich professional environment. Being a station in western province and capital of Colombo, most of the participants and hospital staff are senior and experienced medical officers. Sample was selected using stratified sampling procedure. In the process of stratification of sample of medical officers, the latest salary pay roll details was used. Therefore, it was a good representative sample and internal validity was preserved. Selection bias was minimized by having an appropriate eligibility criterion for the study population and using probability sampling technique with a design effect to select the sample. Random allocation of medical officers in each stratum made it further unbiased.

A good response rate of $90.0 \%$ was achieved. This was done over a very short time period. The most difficult act was to find time out of clinical specialists, who are having tight time schedules both in public and private. They had the lowest response rate (82.9\%) A self-administered questionnaire was used to collect data, considering the standard levels of education of medical officers. Thus, opportunity for interviewer bias was eliminated. Further in this type of subject matter where punitive administrative mindsets make people be defensive and come out with socially acceptable answers, not having an interviewer is conducive for unbiased. It is one of the instruments that could be applied conveniently in this study setting and time frames. This being a novel and controversial subject matter in designing the questionnaire simple language was adhered to. Based on supported literature (Mock et al, 1999 and Landen \& hendrick ,1995) three months recall period was taken. The ability to recall increases with the severity of the incidents. In addition, maximum effort was taken to minimize recall bias.

The questionnaire contained questions which explored the basic knowledge on near misses that should be known by a medical officer. No respondent scored less than $30 \%$. More than half $(52.9 \%)$ had a knowledge score of $75 \%$ or above. The mean knowledge score was 74 out of 100 . Only $5.9 \%$ had poor knowledge. These findings indicate that medical officers had good knowledge on near misses.

In contrast to the level of knowledge, overall a considerable percentage ( $n=168,53 \%$ ) had poor level of practices. Only $5.9 \%$ $(n=19)$ had good level of practices. This finding may be due to the less importance given for prevention of near misses and near miss surveillance is not being carried out.

\section{CONCLUSIONS}

The knowledge on medical near misses was overall satisfactory in all categories of medical officers. In comparison to the satisfactory level of knowledge considerable proportion of medical officers in all categories had poor level of practices. This indicates the less attention paid $b$ on medical near misses. It is recommended that policy makers and medical administrators pay more emphasis on this important preventable area. A near miss surveillance system should be implemented together with regular review meetings.

\section{REFERENCES}

1) Lucian L. Leap, MD, 1994.Error in Medicine, Journal of the American Medical Association.272(23), December 21, P18521857.

2) James Reason 2006, Human error and management, British Medical Journal, Vol 320, March 2000, p768.

3) Prtrice L.Spath, 2011,Error Reduction in health care, Wiley Imprint, USA, p15,61.

4) William Runciman1, Peter Hibbert, Richard Thomson, Tjerk Van Der Schaaf,. 2009, Towards an International Classification for Patient Safety: key concepts and terms, International Journal for Quality in Health Care, Volume 21

5) National patient safety agency, 2004, Seven Steps to Patient Safety, Accessed on 2016/7/30. www.nrls.npsa.nhs.uk p15 


\section{Knowledge and Practices of Medical Officers on Medical Near Misses in a Tertiary Care Hospital, Sri Lanka}

6) The Royal College of Radiologists, Society and College of Radiographers, Institute of Physics and Engineering in Medicine, National Patient Safety Agency, British Institute of Radiology (2008) Towards Safer Radiotherapy. The Royal College of Radiologists, London. www.rcr.ac.uk/index.asp?PagelD=149\&PublicationID=281

7) WHO, 2005, Draft Guidelines for Adverse event Reporting and learning Systems ,WHO press, Geneva, Switzerland, p10.

8) Kohn L, Corrigan J, Donaldson M, Washinton MD,1999, To Err is Human, Institute of Medicine National Academic Press, USA.

9) Elizabeth R. Ransom, Maulik S. Joshi, David B. Nash, and Scott B. Ransom,(2008). Health Care Quality Book. $2^{\text {nd }}$ Edision, AUPHA Press, Washington, pp 4-5.

10) WHO, 2008, A guide to develop knowledge, attitude and practice surveys, WHO press Geneva, p5.

11) WHO, 2011. Evaluating Quality of care for severe pregnancy complications, The WHO near-Miss approach for maternal health. Geveva, WHO press, p7.

12) Wu, A.W. 2000.Medical error: the second victim. The doctor who makes the mistake needs help too, BMJ .320(7237):726-7.

13) National Patient Safety Agency2004, What is a patient safety incident, Available at: www.nrls.npsa.nhs.uk/report-apatient-safety-incident,p15.

14) David W Bates, Itziar Larizgoitia, Nittita Prasopa-Plaizier, Ashish K Jha.2009. Analysis Global Priorities for Patient Safety Research. British Medical Journal. (338:b1775).

15) Donna $O$ et al, 2009. Safety Practices and Outcomes in the U.S. Health Care System. United States. The Agency for Healthcare Research and Quality, p40.

16) Charles Vincent (2010), Patient Safety, $2^{\text {nd }}$ Edition, Wiley-Blackwell, UK, pp192-206..

17) John Tingle and Pipa Bark, 2011, patient safety, Law policy and practice, Routledge, USA, p 165. 